\title{
Further Enlargement
}

National Cancer Institute

\section{Source}

National Cancer Institute. Further Enlargement. NCI Thesaurus. Code C142367.

An increase in size, volume, quantity or scope in comparison to a previous enlarged state. 